\title{
Fluorination effects on the thermodynamic, thermophysical and surface properties of ionic liquids
}

\author{
N.S.M. Vieira ${ }^{\mathrm{a}, 1}$, A. Luís ${ }^{\mathrm{b}, 1}$, P.M. Reis ${ }^{\mathrm{a}}$, P.J. Carvalho ${ }^{\mathrm{b}}$, J.A. Lopes-da-Silva ${ }^{\mathrm{c}}$, J.M.S.S. Esperança ${ }^{\mathrm{a}}$, \\ J.M.M. Araújo a , L.P.N. Rebelo ${ }^{a}$, M.G. Freire ${ }^{b, *}$, A.B. Pereiro ${ }^{a, *}$ \\ a Instituto de Tecnologia Química e Biológica António Xavier, Universidade Nova de Lisboa, 2780-157 Oeiras, Portugal \\ ${ }^{\mathrm{b}}$ CICECO - Aveiro Institute of Materials, Department of Chemistry, University of Aveiro, 3810-193 Aveiro, Portugal \\ ${ }^{\text {c } Q O P N A}$ Unit, Department of Chemistry, University of Aveiro, 3810-193 Aveiro, Portugal
}

\section{A R T I C L E I N F O}

\section{Article history:}

Received 7 September 2015

Received in revised form 1 February 2016

Accepted 14 February 2016

Available online 21 February 2016

\section{Keywords:}

Fluorinated ionic liquids

Surface tension

Physical and thermal properties

Thermodynamic functions

Walden plot

\begin{abstract}
A B S T R A C T
This paper reports the thermal, thermodynamic, thermophysical and surface properties of eight ionic liquids with fluorinated alkyl side chain lengths equal or greater than four carbon atoms. Melting and decomposition temperatures were determined together with experimental densities, surface tensions, refractive indices, dynamic viscosities and ionic conductivities in a temperature interval ranging from (293.15 to 353.15) K. The surface properties of these fluorinated ionic liquids were discussed and several thermodynamic functions, as well as critical temperatures, were estimated. Coefficients of isobaric thermal expansion, molecular volumes and free volume effects were calculated from experimental values of density and refractive index and compared with previous data. Finally, Walden plots were used to evaluate the ionicity of the investigated ionic liquids.
\end{abstract}

(ㄷ) 2016 Elsevier Ltd. All rights reserved.

\section{Introduction}

In recent years, ionic liquids (ILs) have been the object of study for different purposes by a large community of researchers. The main focus has been on their thermophysical characterization [1-4] and toxicity evaluation [5-7]. Many different families of ILs have been scrutinized for distinct applications. Due to their properties, ILs are generally considered safer than conventional, volatile solvents, and are already in use in different industrial processes $[8,9]$. In biological applications, ILs have been tested for their potential contribution towards the improvement of different classes of drugs, mainly regarding the solubility increment of poorly soluble ones [10-13] and also for the development of oxygen therapeutics $[7,14]$. Fluorinated ionic liquids (FILs) constitute a specific family of ILs which might bring together the general best characteristics of ionic liquids with the unique chemical and biological inertness of perfluorocarbons (PFCs) $[7,15,16]$. Therefore, they have great potential in the biomedical sciences while favorable toxicity profiles suggest additional applications in the health

\footnotetext{
* Corresponding authors. Tel.: +351 214469471; fax: +351214411277.

E-mail addresses: maragfreire@ua.pt (M.G. Freire), anab@itqb.unl.pt (A.B. Pereiro).

${ }^{1}$ Equally contributing authors.
}

area [7]. ILs are also promising as components in innovative biomaterials [17].

In contrast with traditional fluoro-containing ILs (e.g. those based on hexafluorophosphate or tetrafluoroborate or bis(trifluoro methylsulfonyl)imide) FILs are ionic liquids with long fluoroalkyl chain tails, and, therefore, they are markedly distinct from mere fluoro-containing ionic liquids; inherently, these fluoroalkyl chains are able to form segregated fluorinated (nonpolar) domains as was previously proven [18]. The properties of neoteric FILs may combine exceptional assets such as high thermal and electrochemical stability, high ionic conductivity, null flammability and low surface tension. These characteristics are likely to enable the design of different materials for a wide range of applications [7,19]. The selfaggregation behavior of some FILs in aqueous solutions induces the formation of self-assembled structures that can be used advantageously in the delivery of different compounds [20]. These new biomaterials can be developed based on a proper combination of the three existing nanodomains in FILs (one polar and two nonpolar (one hydrogenated and one fluorinated)) [18]. The relative size of these domains will determine the final properties of FILs such as solubility, polarity, and hydrophobicity/hydrophilicity [18].

The main goal of this paper is the thermodynamic, thermophysical and surface characterization of different FILs with different combinations of cations (tetrabutylammonium, cholinium, 1-ethyl-3-methylpyridinium, 1-ethyl-1-methylpyrrolidinium and 
1-butyl-1-methylpyrrolidinium) and anions (perfluorobutanesulfonate, perfluorooctanesulfonate, bis(nonafluorobutylsulfonyl)imi de and perfluoropentanoate). With this goal in mind, several experimental measurements of thermodynamic and thermophysical properties including surface tension were carried out. Additionally, the hypothetical critical temperatures of these ILs were also estimated by means of the Eötvös [21] and Guggenheim equations [22]. Furthermore, the coefficient of thermal expansion, the molar free volume and Walden plots were also studied.

\section{Experimental section}

\subsection{Chemicals}

Tetrabutylammonium perfluorooctanesulfonate, [ $\left.\mathrm{N}_{4444}\right]$ $\left[\mathrm{C}_{8} \mathrm{~F}_{17} \mathrm{SO}_{3}\right]$ (0.98 mass fraction purity, 0.0012 molar fraction halide impurities), tetrabutylammonium perfluorobutanesulfonate, $\left[\mathrm{N}_{4444}\right]\left[\mathrm{C}_{4} \mathrm{~F}_{9} \mathrm{SO}_{3}\right]$ (0.98 mass fraction purity, 0.0011 molar fraction halide impurities), 1-ethyl-3-methylpyridinium perfluorobutanesulfonate, $\left[\mathrm{C}_{2} \mathrm{C}_{1}\right.$ py $]\left[\mathrm{C}_{4} \mathrm{~F}_{9} \mathrm{SO}_{3}\right]$ (0.99 mass fraction purity, 0.00004 molar fraction halide impurities), cholinium ((2-hydroxyethyl)tri methylammonium) perfluorobutanesulfonate, $\left[\mathrm{N}_{1112(\mathrm{OH})}\right]\left[\mathrm{C}_{4} \mathrm{~F}_{9} \mathrm{SO}_{3}\right]$ (0.97 mass fraction purity, 0.00326 molar fraction halide impurities), cholinium ((2-hydroxyethyl)trimethylammonium) bis(nonafluorobutylsulfonyl)imide, $\left[\mathrm{N}_{1112(\mathrm{OH})}\right]\left[\mathrm{N}\left(\mathrm{C}_{4} \mathrm{~F}_{9} \mathrm{SO}_{2}\right)_{2}\right](0.97$ mass fraction purity, 0.00085 molar fraction halide impurities), 1-ethyl-1-methylpyrrolidinium bis(nonafluorobutylsulfonyl)imid e, [ $\mathrm{C}_{2} \mathrm{C}_{1}$ pyr] $\left[\mathrm{N}\left(\mathrm{C}_{4} \mathrm{~F}_{9} \mathrm{SO}_{2}\right)_{2}\right]$ (0.97 mass fraction purity, 0.006 molar fraction halide impurities), and 1-butyl-1-methylpyrrolidinium bi $\mathrm{s}$ (nonafluorobutylsulfonyl)imide, $\quad\left[\mathrm{C}_{4} \mathrm{C}_{1} \mathrm{pyr}\right]\left[\mathrm{N}\left(\mathrm{C}_{4} \mathrm{~F}_{9} \mathrm{SO}_{2}\right)_{2}\right] \quad(0.98$ mass fraction purity, 0.0013 molar fraction halide impurities), were supplied by IoLiTec GmbH. To reduce the volatile chemicals and water contents, all FILs were dried under vacuum $\left(3 \cdot 10^{-2}\right.$ Torr $)$ with vigorous stirring at $T=323.15 \mathrm{~K}$ for at least 2 days, immediately prior to their use. No further purification was carried out and the purity of all FILs was checked by ${ }^{1} \mathrm{H},{ }^{13} \mathrm{C}$ and ${ }^{19} \mathrm{~F}$ NMR.

The synthesis of 1-ethyl-3-methylpyridinium perfluoropentanoate, $\left[\mathrm{C}_{2} \mathrm{C}_{1}\right.$ py] $\left[\mathrm{C}_{4} \mathrm{~F}_{9} \mathrm{CO}_{2}\right]$, was made through the ion exchange resin method, as developed by Ohno et al. [23] and also implemented in our laboratory [4,13]. $4.77 \mathrm{~mL}(0.030 \mathrm{~mol}$; M.W. $=264.05 \mathrm{~g} / \mathrm{mol} ; \rho=1.713 \mathrm{~g} / \mathrm{mL}$ at $T=298 \mathrm{~K}, 97 \%)$ of perfluoropentanoic acid was dissolved in water. $6.06 \mathrm{~g}$ of $\left[\mathrm{C}_{2} \mathrm{C}_{1} \mathrm{py}\right] \mathrm{Br}$ (M.W. $=202.1 \mathrm{~g} / \mathrm{mol} ; 0.030 \mathrm{~mol})$ was dissolved in water $(25 \mathrm{~mL})$ and added to an anionic exchange resin. The solution was titrated until a $\mathrm{pH}=7$ was achieved and then evaporated in a rotavapour apparatus. The orange oil obtained was dried in a vacuum line ( $3 \cdot 10^{-2}$ Torr). During the drying process at $T=323.15 \mathrm{~K}$ the orange liquid becomes darker. This compound was completely characterized by ${ }^{1} \mathrm{H}$ and ${ }^{19} \mathrm{~F}$ NMR and elemental analysis was carried out in order to check its final purity. ${ }^{1} \mathrm{H}$ NMR $(400 \mathrm{MHz}$, $\left(\mathrm{CDCl}_{3}\right): \delta 9.24(\mathrm{~s}, 1 \mathrm{H}, \mathrm{py}) ; 9.18(\mathrm{~d}, 1 \mathrm{H}, \mathrm{py}) ; 8.18(\mathrm{~d}, 1 \mathrm{H}, \mathrm{py}) ; 7.91$ $(\mathrm{t}, 1 \mathrm{H}, \mathrm{py}) ; 4.88\left(\mathrm{q}, 2 \mathrm{H}, \mathrm{CH}_{3} \mathrm{CH}_{2} \mathrm{~N}\right) ; 2.60\left(\mathrm{~s}, 3 \mathrm{H}, \mathrm{CH}_{3} \mathrm{py}\right) ; 1.65(\mathrm{t}$, $\left.3 \mathrm{H}, \mathrm{CH}_{3} \mathrm{CH}_{2} \mathrm{~N}\right) .{ }^{19} \mathrm{~F}$ NMR $\left(376 \mathrm{MHz},\left(\mathrm{CDCl}_{3}\right): \delta-81.02\left(\mathrm{CF}_{3}\right)\right.$; $-116.40\left(\mathrm{CF}_{2} \mathrm{CO}_{2}\right) ;-123.20\left(\mathrm{CF}_{3} \mathrm{CF}_{2} \mathrm{CF}_{2}\right) ;-126.02\left(\mathrm{CF}_{3} \mathrm{CF}_{2}\right)$. Elemental analysis calculated (found): \% C 40.53 (40.85); \% H 3.14 (3.21); \% N 3.64 (3.52), with a standard uncertainty of $\pm 0.4 \%$. The NMR spectra also confirmed the expected cation/anion identities by a quantitative integration of their characteristic ${ }^{1} \mathrm{H}$ and ${ }^{19} \mathrm{~F}$ resonance peaks, using fluorobenzene (99\%; Alfa Aesar, Karlsruhe, Germany) as internal standard. Additionally, the ${ }^{1} \mathrm{H}$ NMR spectra indicates a molar fraction purity of 0.99 (NMR spectra are available at $\mathrm{SI}$ ).

The chemical structures of the fluorinated ionic liquids studied in this work are presented in table 1 . The water content of these FILs was analyzed by Karl Fischer (KF) titration technique
(Metrohm Ion analysis, $831 \mathrm{KF}$ Coulometer). The water content was less than $100 \mathrm{ppm}$ for all the studied fluorinated ionic liquids.

\subsection{Experimental procedures}

Each fluorinated ionic liquid was taken from its schlenk flask with a syringe under a nitrogen flow to prevent humidity uptake and was immediately placed in the respective apparatuses.

\subsubsection{Thermal properties}

Thermogravimetric analyses (TGA) were carried out with a TA instrument Model TGA Q50 and the thermal stabilities and decomposition temperatures of the fluorinated ionic liquids were measured. Nitrogen was used in the TGA measurements at a flow rate of $60 \mathrm{~mL} \cdot \mathrm{min}^{-1}$. Samples were placed inside aluminum pans and heated up to $T=873 \mathrm{~K}$ at a rate of $1 \mathrm{~K} \cdot \mathrm{min}^{-1}$ until complete thermal degradation was achieved. The degradation temperatures were determined where starting $\left(T_{\text {start }}\right)$, onset $\left(T_{\text {onset }}\right)$ and decomposition $\left(T_{\mathrm{dec}}\right)$ temperature correspond to the temperature at which the compound's weight loss was less than $1 \%$, the baseline slope changed during heating and the temperature at which the compound's weight loss was $50 \%$, respectively. The determination of these temperatures was performed using the Universal Analysis, version $4.4 \mathrm{~A}$ software.

A DSC Q200 Differential Scanning Calorimeter (TA Instrument) was used to measure the thermal properties of the fluorinated ionic liquids. The sample was continuously purged with $50 \mathrm{~mL} \cdot \mathrm{min}^{-1}$ nitrogen. About 5 to $10 \mathrm{mg}$ of fluorinated IL was crimped in a standard aluminum hermetic sample pan. Indium (m.p., $T=429.76 \mathrm{~K}$ ) was used as the standard compound for the calibration of the DSC. Only melting points are reported in this work, all other phase transitions will be reported in the next publication.

\subsubsection{Surface tension}

The surface tension of each FIL was determined in the temperature range between (298.15 and 353.15$) \mathrm{K}$, at atmospheric pressure, using the pendant drop method. The measurements were performed through the analysis of the shape of the pendant drop using a Dataphysics contact angle system OCA-20. Drop volumes of $(6 \pm 1) \mu \mathrm{L}$ were obtained using a Hamilton DS 500/GT syringe connected to a Teflon coated needle placed inside an aluminum chamber able to maintain the temperature within $\pm 0.1 \mathrm{~K}$. The temperature was attained by circulating water in a double jacketed aluminum cell by means of a Julabo F-25 water bath. The temperature inside the aluminum chamber was measured with a Pt100 probe within $\pm 0.02 \mathrm{~K}$ (placed at a distance of approximately $2 \mathrm{~cm}$ of the liquid drop). After reaching a specific temperature, the measurements were carried out after $30 \mathrm{~min}$ to guarantee the thermal stabilization of the drop. Silica gel was kept inside the air chamber to keep a dry environment. For the surface tensions determination at each temperature, and for each FIL, at least six drops were formed and measured. For each drop, an average of 200 images was captured. The analysis of the drop shape was executed with the software module SCA 20 in which the gravitational acceleration and latitude were used according to the location of the assay. The feasibility of this technique to determine the surface tensions of ILs was previously addressed [24].

\subsubsection{Density and Viscosity}

Measurements of viscosity and density were performed at atmospheric pressure in the temperature range between (293.15 and 353.15) K using an automated SVM 3000 Anton Paar rotational Stabinger (viscometer + densimeter). The SVM 3000 uses Peltier elements for fast and efficient thermostability. The standard uncertainty of temperature is $\pm 0.02 \mathrm{~K}$. The reproducibility of the 
TABLE 1

Chemical structure and acronyms of the fluorinated ionic liquids (FILs) used in this work

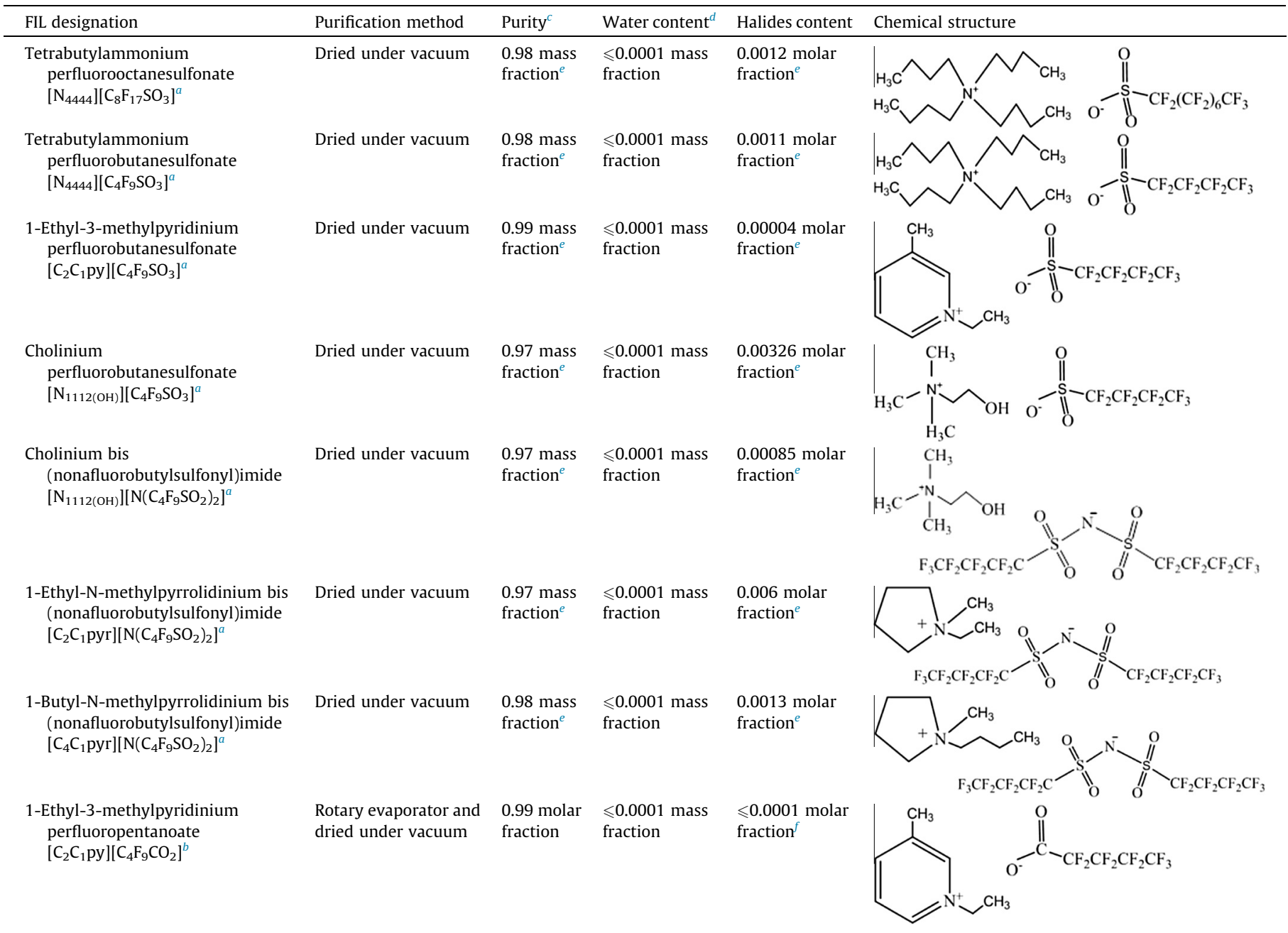

a Supplied byloLiTec Gmbh.

${ }^{b}$ Synthesized in our lab.

${ }^{c}$ Purity was determined by NMR.

${ }^{d}$ Water content was analyzed by Karl Fischer (KF) titration technique (Metrohm Ion analysis, 831 KF Coulometer).

e As stated by the supplier.

${ }^{f}$ Negative for $\mathrm{AgNO}_{3}$ testing.

dynamic viscosity and the density is $\pm 1 \%$ and $\pm 0.0002 \mathrm{~g} \cdot \mathrm{cm}^{-3}$, respectively. For each fluorinated ionic liquid, triplicates were measured and the reported result is the average value with a maximum relative standard deviation (RSD) of $0.56 \%$ for the viscosity and $\pm 0.03 \%$ for the density. The expanded uncertainty with a 0.95 level of confidence (taking into account the purity and handling of the samples) of the measurements is estimated to be $2 \%$ for the viscosity and $0.1 \%$ for the density.

\subsubsection{Ionic conductivity measurements}

A CDM 210 Radiometer Analytical conductivimeter (CDC749 electrode) was used to measure the ionic conductivities of FILs in a glass cell containing a magnetic stirrer. The cell was closed with screw caps to ensure a secure seal and flushed with dry nitrogen to prevent humidity uptake. A water bath controlled to $T= \pm 0.01 \mathrm{~K}$ was used to thermostatize the glass cell. The temperature of the glass cell was measured by means of a platinum resistance thermometer coupled to a Keithley 199 System DMM/Scanner. The thermometer was calibrated against high-accuracy mercury ther- mometers $(T=0.01 \mathrm{~K})$. The conductivimeter was calibrated at each temperature with certified $0.01 \mathrm{D}(\mathrm{D}=$ demal $)$ and $0.1 \mathrm{D} \mathrm{KCl} \mathrm{stan-}$ dard solutions supplied by Radiometer Analytical. This conductivimeter uses an alternating current of $12 \mathrm{~V}$ and a frequency of $2.93 \mathrm{kHz}$ in the range of conductivities measured in this work. This technique was validated using pure ionic liquids as described previously [25]. Every conductivity value was determined at least two times and the expanded uncertainty with a 0.95 level of confidence of the measurements is estimated to be $1 \%$ in absolute value.

\subsubsection{Refractive index}

The refractive index of the pure fluorinated ionic liquids was determined by an ABBEMAT 500 Anton Paar automatic refractometer at $589 \mathrm{~nm}$ with a resolution of $\pm 10^{-6}$ and an expanded uncertainty with a 0.95 level of confidence uncertainty in the experimental measurements of $\pm 4 \cdot 10^{-5}$. The apparatus was calibrated by measuring the refractive index of Millipore quality water and tetrachloroethylene (provided by the supplier) before each series of measurements. 


\section{Results and discussion}

\subsection{Thermal properties}

The degradation (start, onset and decomposition) and the melting temperatures are listed in table 2. Figures S3-S7 given as Supporting Information illustrate the DSC curves of the FILs studied in this work. The onset temperature versus the melting temperature of the FILs is plotted in figure 1 . These thermal properties determine the liquid range and the upper operating temperature of these FILs and consequently the useful conditions for their application. Our results indicate that only $\left[\mathrm{N}_{1112(\mathrm{OH})}\right]\left[\mathrm{C}_{4} \mathrm{~F}_{9} \mathrm{SO}_{3}\right],\left[\mathrm{C}_{2} \mathrm{C}_{1} \mathrm{pyr}\right]$ $\left[\mathrm{N}\left(\mathrm{C}_{4} \mathrm{~F}_{9} \mathrm{SO}_{2}\right)_{2}\right]$ and $\left[\mathrm{C}_{4} \mathrm{C}_{1} \mathrm{pyr}\right]\left[\mathrm{N}\left(\mathrm{C}_{4} \mathrm{~F}_{9} \mathrm{SO}_{2}\right)_{2}\right]$ exhibit melting temperatures higher than $373.15 \mathrm{~K}$ which restricts their function as neat compounds. However, the latter $\left(\left[\mathrm{C}_{4} \mathrm{C}_{1} \mathrm{pyr}\right]\left[\mathrm{N}\left(\mathrm{C}_{4} \mathrm{~F}_{9} \mathrm{SO}_{2}\right)_{2}\right]\right)$ still presents a reasonably melting transition. The differences in terms of melting points between the carboxylate and the sulfonate anions are insignificant for FILs based on the pyridinium cation. However, FILs based on $\left[\mathrm{C}_{4} \mathrm{~F}_{9} \mathrm{SO}_{3}\right]^{-}$and $\left[\mathrm{N}\left(\mathrm{C}_{4} \mathrm{~F}_{9} \mathrm{SO}_{2}\right)_{2}\right]^{-}$show higher decomposition temperatures than FILs based on $\left[\mathrm{C}_{4} \mathrm{~F}_{9} \mathrm{CO}_{2}\right]^{-}$. Therefore, the most appropriated FILs for the development of new innovative biomaterials, based on their thermal properties, are $\left[\mathrm{N}_{4444}\right]$ $\left[\mathrm{C}_{4} \mathrm{~F}_{9} \mathrm{SO}_{3}\right],\left[\mathrm{C}_{2} \mathrm{C}_{1}\right.$ py] $\left[\mathrm{C}_{4} \mathrm{~F}_{9} \mathrm{SO}_{3}\right]$ and $\left[\mathrm{N}_{1112(\mathrm{OH})}\right]\left[\mathrm{N}\left(\mathrm{C}_{4} \mathrm{~F}_{9} \mathrm{SO}_{2}\right)_{2}\right]$.

The anion effect can be evaluated for FILs based on the cholinium cation combined with perfluorobutanesulfonate, $\left[\mathrm{C}_{4} \mathrm{~F}_{9} \mathrm{SO}_{3}\right]^{-}$, and bis(nonafluorobutylsulfonyl)imide, $\left[\mathrm{N}\left(\mathrm{C}_{4} \mathrm{~F}_{9} \mathrm{SO}_{2}\right)_{2}\right]^{-}$. The results show that the presence of $\left[\mathrm{N}_{(}\left(\mathrm{C}_{4} \mathrm{~F}_{9} \mathrm{SO}_{2}\right)_{2}\right]^{-}$decreases the melting temperature and increases the decomposition temperature. On the other hand, the effect of the cation was studied for the perfluorobutanesulfonate anion with three different cations: ammonium, cholinium and pyridinium. In this case, the melting temperature decreases in the following order: $\left[\mathrm{N}_{1112(\mathrm{OH})}\right]^{+}>$ $\left[\mathrm{N}_{4444}\right]^{+}>\left[\mathrm{C}_{2} \mathrm{C}_{1} \mathrm{py}\right]^{+}$. Furthermore, in terms of decomposition temperature, $\left[\mathrm{C}_{2} \mathrm{C}_{1} \mathrm{py}\right]^{+}$shows the highest stability in contrast to $\left[\mathrm{N}_{4444}\right]^{+}$[7] presenting the lowest decomposition temperature. Another comparison shows us that for the bis(nonafluorobutylsul fonyl)imide anion the melting temperature of FILs based on the pyrrolidium cation is higher than for FILs based on cholinium. On the other hand, the increment of the fluorinated chain length for FILs based on ammonium decreases both the melting and decomposition temperatures [7]. Finally, the higher decomposition temperatures of FILs based on $\left[\mathrm{C}_{4} \mathrm{~F}_{9} \mathrm{SO}_{3}\right]^{-}$combined with their lower melting points allows for their use in a wider range of conditions as clearly depicted in figure 1 .

\subsection{Surface properties}

Due to the high melting point of some FILs, surface tensions were only determined for five of them, namely [ $\left.\mathrm{N}_{4444}\right]\left[\mathrm{C}_{8} \mathrm{~F}_{17} \mathrm{SO}_{3}\right]$, $\left[\mathrm{N}_{4444}\right]\left[\mathrm{C}_{4} \mathrm{~F}_{9} \mathrm{SO}_{3}\right], \quad\left[\mathrm{C}_{2} \mathrm{C}_{1}\right.$ py $]\left[\mathrm{C}_{4} \mathrm{~F}_{9} \mathrm{SO}_{3}\right], \quad\left[\mathrm{C}_{2} \mathrm{C}_{1}\right.$ py $]\left[\mathrm{C}_{4} \mathrm{~F}_{9} \mathrm{CO}_{2}\right]$ and $\left[\mathrm{N}_{1112(\mathrm{OH})}\right]\left[\mathrm{N}\left(\mathrm{C}_{4} \mathrm{~F}_{9} \mathrm{SO}_{2}\right)_{2}\right]$. Values of the surface tensions of each FIL at different temperatures are listed in table 3 and plotted in figure 2. The surface tension of these FILs shows a strong temperature dependence, and for the studied temperature range the surface tension of FILs decreases in the following order: $\left[\mathrm{C}_{2} \mathrm{C}_{1}\right.$ py] $\left[\mathrm{C}_{4} \mathrm{~F}_{9} \mathrm{CO}_{2}\right] \approx\left[\mathrm{C}_{2} \mathrm{C}_{1}\right.$ py $]\left[\mathrm{C}_{4} \mathrm{~F}_{9} \mathrm{SO}_{3}\right]>\left[\mathrm{N}_{1112(\mathrm{OH})}\right]\left[\mathrm{N}\left(\mathrm{C}_{4} \mathrm{~F}_{9} \mathrm{SO}_{2}\right)_{2}\right]>\left[\mathrm{N}_{4444}\right]$ $\left[\mathrm{C}_{4} \mathrm{~F}_{9} \mathrm{SO}_{3}\right]>\left[\mathrm{N}_{4444}\right]\left[\mathrm{C}_{8} \mathrm{~F}_{17} \mathrm{SO}_{3}\right]$. It is a fact that the surface tension of FILs is substantially lower than that of non-fluorinated ionic liquids and similar to that of common organic solvents [26], although the surface tension of FILs is higher than that of perfluorocarbons [27]. The increment of the anion's fluorinated alkyl chain size in FILs based on the ammonium cation leads to an important reduction of the surface tension (when comparing $\left[\mathrm{N}_{4444}\right]\left[\mathrm{C}_{4} \mathrm{~F}_{9} \mathrm{SO}_{3}\right]$ with $\left.\left[\mathrm{N}_{4444}\right]\left[\mathrm{C}_{8} \mathrm{~F}_{17} \mathrm{SO}_{3}\right]\right)$. On the other hand, the change from a carboxylate to a sulfonate anion with the same perfluoroalkyl
TABLE 2

Degradation properties (start temperature $\left(T_{\text {start }}\right)^{a}$, onset temperature $\left(T_{\text {onset }}\right)^{a}$, decomposition temperature $\left.\left(T_{d e c}\right)^{a}\right)$ and melting point $\left(T_{m}\right)^{b}$ of the studied fluorinated ionic liquids. Experiments performed under a typical average laboratory atmospheric pressure of 1.015 bar.

\begin{tabular}{|c|c|c|c|c|}
\hline & $T_{\text {start }} / \mathrm{K}$ & $T_{\text {onset }} / \mathrm{K}$ & $T_{\mathrm{dec}} / \mathrm{K}$ & $T_{\mathrm{m}} / \mathrm{K}$ \\
\hline$\left[\mathrm{N}_{4444}\right]\left[\mathrm{C}_{8} \mathrm{~F}_{17} \mathrm{SO}_{3}\right]^{d}$ & 374 & 385 & 403 & 255 \\
\hline$\left[\mathrm{N}_{4444}\right]\left[\mathrm{C}_{4} \mathrm{~F}_{9} \mathrm{SO}_{3}\right]^{d}$ & 545 & 587 & 619 & 327 \\
\hline$\left[\mathrm{C}_{2} \mathrm{C}_{1} \mathrm{py}\right]\left[\mathrm{C}_{4} \mathrm{~F}_{9} \mathrm{SO}_{3}\right]^{d}$ & 574 & 629 & 652 & 278 \\
\hline$\left[\mathrm{N}_{1112(\mathrm{OH})}\right]\left[\mathrm{C}_{4} \mathrm{~F}_{9} \mathrm{SO}_{3}\right]$ & 573 & 609 & 631 & $436(5 \mathrm{~K} / \mathrm{min})^{c}$ \\
\hline$\left[\mathrm{N}_{1112(\mathrm{OH})}\right]\left[\mathrm{N}\left(\mathrm{C}_{4} \mathrm{~F}_{9} \mathrm{SO}_{2}\right)_{2}\right]$ & 575 & 622 & 633 & $303(5 \mathrm{~K} / \mathrm{min})^{e}$ \\
\hline$\left[\mathrm{C}_{2} \mathrm{C}_{1} \mathrm{pyr}\right]\left[\mathrm{N}\left(\mathrm{C}_{4} \mathrm{~F}_{9} \mathrm{SO}_{2}\right)_{2}\right]$ & 562 & 619 & 638 & $428(5 \mathrm{~K} / \mathrm{min})^{c}$ \\
\hline$\left[\mathrm{C}_{4} \mathrm{C}_{1}\right.$ pyr $]\left[\mathrm{N}\left(\mathrm{C}_{4} \mathrm{~F}_{9} \mathrm{SO}_{2}\right)_{2}\right]$ & 587 & 639 & 656 & $371(1 \mathrm{~K} / \mathrm{min})^{t}$ \\
\hline$\left[\mathrm{C}_{2} \mathrm{C}_{1} \mathrm{py}\right]\left[\mathrm{C}_{4} \mathrm{~F}_{9} \mathrm{CO}_{2}\right]$ & 375 & 392 & 408 & $275(1 \mathrm{~K} / \mathrm{min})^{c}$ \\
\hline
\end{tabular}

${ }^{a}$ Note that these values are from scanning TGA, and do not represent isothermal stabilities. Standard uncertainty is estimated as $T= \pm 4 \mathrm{~K}$.

${ }^{b}$ Standard uncertainty is estimated as $T= \pm 2 \mathrm{~K}$.

c Standard uncertainty of \pm 0.01 bar.

${ }^{d}$ From reference [7].

${ }^{e}$ Melting temperatures were determined by DSC using the onset temperature at the specified heating rate.

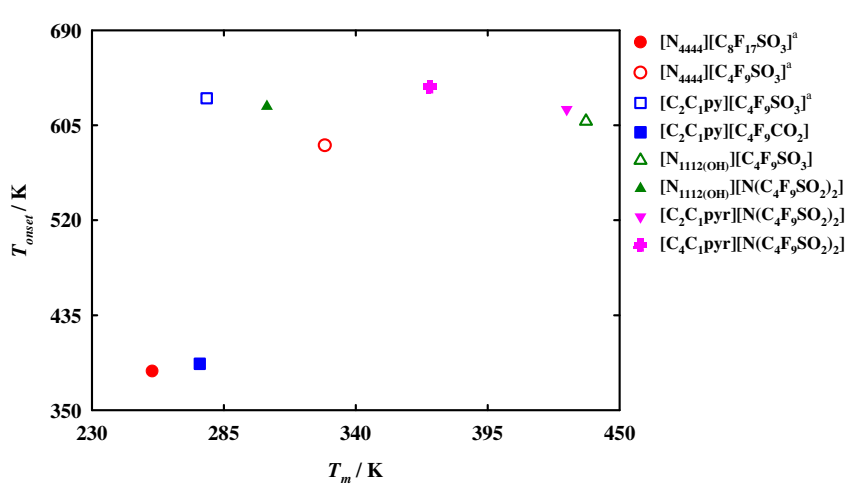

FIGURE 1. Decomposition onset temperature versus melting temperature of the studied FILs and comparison with previous experimental data ( ${ }^{a}$ from reference [7]).

TABLE 3

Experimental surface tension of the studied fluorinated ionic liquids. Experiments performed under a typical average laboratory atmospheric pressure of 1.015 bar. $^{a}$

\begin{tabular}{|c|c|c|c|c|c|}
\hline$T^{b} / \mathrm{K}$ & $\gamma^{c} / \mathrm{mN} \cdot \mathrm{m}^{-1}$ & $T^{b} / \mathrm{K}$ & $\gamma^{c} / \mathrm{mN} \cdot \mathrm{m}^{-1}$ & $T^{b} / \mathrm{K}$ & $\gamma^{c} / \mathrm{mN} \cdot \mathrm{m}^{-1}$ \\
\hline \multicolumn{2}{|c|}{$\left[\mathrm{N}_{4444}\right]\left[\mathrm{C}_{8} \mathrm{~F}_{17} \mathrm{SO}_{3}\right]$} & \multicolumn{2}{|c|}{$\left[\mathrm{N}_{4444}\right]\left[\mathrm{C}_{4} \mathrm{~F}_{9} \mathrm{SO}_{3}\right]$} & \multicolumn{2}{|c|}{$\left[C_{2} C_{1} p y\right]\left[C_{4} F_{9} S_{3}\right]$} \\
\hline 298.4 & 21.98 & 333.1 & 22.77 & 298.3 & 26.35 \\
\hline 303.2 & 21.60 & 338.0 & 22.57 & 303.4 & 26.16 \\
\hline 313.3 & 21.11 & 343.1 & 22.36 & 313.4 & 25.77 \\
\hline 323.2 & 20.65 & 348.3 & 22.20 & 323.6 & 25.39 \\
\hline 333.2 & 20.14 & 353.4 & 21.95 & 332.9 & 25.12 \\
\hline 343.0 & 19.55 & & & 343.0 & 24.70 \\
\hline \multicolumn{2}{|c|}{$\left[C_{2} C_{1} p y\right]\left[C_{4} F_{9} C O_{2}\right]$} & \multicolumn{2}{|c|}{$\left[\mathrm{N}_{1112(\mathrm{OH})}\right]\left[\mathrm{N}\left(\mathrm{C}_{4} \mathrm{~F}_{9} \mathrm{SO}_{2}\right)_{2}\right]$} & & \\
\hline 298.3 & 26.83 & 313.4 & 25.04 & & \\
\hline 308.2 & 26.49 & 323.4 & 24.39 & & \\
\hline 317.9 & 26.07 & 333.3 & 23.80 & & \\
\hline 328.0 & 25.71 & 343.4 & 23.24 & & \\
\hline 338.0 & 25.31 & 353.5 & 22.67 & & \\
\hline 347.0 & 24.94 & & & & \\
\hline
\end{tabular}

a Standard uncertainty of \pm 0.01 bar.

${ }^{b}$ Standard uncertainty of $T= \pm 0.1 \mathrm{~K}$.

${ }^{c}$ Expanded uncertainty is \pm 0.13 with a 0.95 level of confidence.

chain length has a very small effect on the surface tension. A comparison between the nature of the cation on the surface tension shows that the surface tensions of FILs based on the pyridinium cation are greater than those observed for FILs based on quaternary ammonium-based cations (either for tetrabutylammonium or cholinium). According to the Langmuir principle, only the parts of the ions that are at the outer surface will significantly contribute 


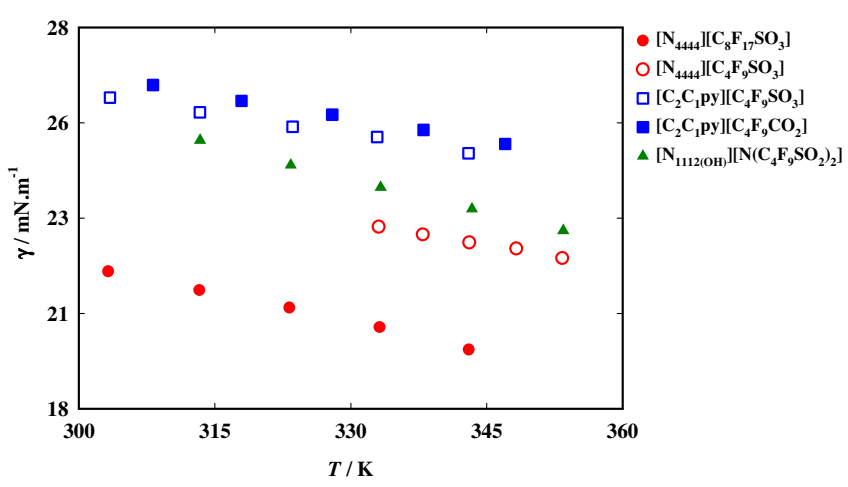

FIGURE 2. Surface tension as a function of temperature for the studied FILs.

to the surface tension. Some reports have highlighted a general segregation between the polar and non-polar parts of the ions and that the longer alkyl side chains point towards the vapor phase $[24,28,29]$, and thus, the surface tensions have been primarily defined by a cation effect. In this work, it is clearly demonstrated that the anion has a dominant effect through the surface tension values, particularly when comparing $\left[\mathrm{N}_{4444}\right]\left[\mathrm{C}_{4} \mathrm{~F}_{9} \mathrm{SO}_{3}\right]$ with $\left[\mathrm{N}_{4444}\right]\left[\mathrm{C}_{8} \mathrm{~F}_{17} \mathrm{SO}_{3}\right]$, suggesting that the IL fluorinated alkyl side chains are pointing towards the vapor phase. Nevertheless, it should be kept in mind that both the cation and the anion contribute to the organization of the surface.

The surface entropy, $S^{\gamma}$, and the surface enthalpy, $H^{\gamma}$, were calculated using the quasi-linear dependence of the surface tension on temperature [26]:

$S^{\gamma}=-\left(\frac{d \gamma}{d T}\right)_{P}$

$H^{\gamma}=\gamma-T\left(\frac{d \gamma}{d T}\right)_{P}$

where $\gamma$ stands for the surface tension and $T$ for the temperature. These values of the thermodynamic properties of FILs, listed in table 4 , are lower than those shown previously for non-fluorinated ILs [30-32] indicating a highly structured liquid phase. This highly structured liquid phase has been recently addressed by some of the authors [20] for different perfluorosulfonate-functionalized ionic liquids. Moreover, both $S^{\gamma}$ and $H^{\gamma}$ increase with the increase of the anion fluorinated moiety - a trend in agreement with that reported with the increase of non-fluorinated alkyl side chain lengths at the cation [24]. Finally, $\left[\mathrm{N}_{1112(\mathrm{OH})}\right]\left[\mathrm{N}\left(\mathrm{C}_{4} \mathrm{~F}_{9} \mathrm{SO}_{2}\right)_{2}\right]$ is the IL with higher $S^{\gamma}$ and $H^{\gamma}$ values which reflect the lower surface organization of this fluid.

Critical temperatures are used in many corresponding state correlations regarding the equilibrium and transport properties. For ionic liquids they are hypothetical quantities, yet still useful as originally shown $[33,34]$ by us. They can be estimated using empirical equations such as the Eötvös [21] or Guggenheim [22]:

$\gamma\left(\frac{M}{\rho}\right)^{2 / 3}=K_{\text {Eot }}\left(T_{\text {c,Eot }}-T\right)$

$\gamma=K_{\mathrm{Gug}}\left(1-\frac{T}{T_{\mathrm{c}, \mathrm{Gug}}}\right)^{11 / 9}$

where $M$ is the molecular weight, $\rho$ is the density, $K_{\text {Eot }}$ and $K_{\text {Gug }}$ are fitted parameters, $T_{\mathrm{c}, \text { Eot }}$ and $T_{\mathrm{c}, \mathrm{Gug}}$ are the critical temperature, and $\gamma$ is the temperature dependent surface tension $\left(\gamma=0\right.$ at $\left.T_{\mathrm{c}}\right)$. The values of the critical temperature are thus obtained by extrapolation of $\gamma$ as a function of $T$ and are shown in table 5 . It should be noted that
TABLE 4

Surface thermodynamic functions of the studied fluorinated ionic liquids.

\begin{tabular}{lll}
\hline & $10^{5} \cdot \mathrm{S}^{\gamma} / \mathrm{J} \cdot \mathrm{m}^{-2} \cdot \mathrm{K}^{-1}$ & $10^{2} \cdot \mathrm{H} / \mathrm{J} \cdot \mathrm{m}^{-2}$ \\
\hline$\left[\mathrm{N}_{4444}\right]\left[\mathrm{C}_{8} \mathrm{~F}_{17} \mathrm{SO}_{3}\right]$ & 5.2 & 3.8 \\
{$\left[\mathrm{~N}_{4444}\right]\left[\mathrm{C}_{4} \mathrm{~F}_{9} \mathrm{SO}_{3}\right]$} & 4.0 & 3.6 \\
{$\left[\mathrm{C}_{2} \mathrm{C}_{1} \mathrm{py}\right]\left[\mathrm{C}_{4} \mathrm{~F}_{9} \mathrm{SO}_{3}\right]$} & 3.6 & 3.7 \\
{$\left[\mathrm{C}_{2} \mathrm{C}_{1} \mathrm{py}\right]\left[\mathrm{C}_{4} \mathrm{~F}_{9} \mathrm{CO}_{2}\right]$} & 3.9 & 3.8 \\
{$\left[\mathrm{~N}_{1112(\mathrm{OH})}\right]\left[\mathrm{N}_{\left.\left(\mathrm{C}_{4} \mathrm{~F}_{9} \mathrm{SO}_{2}\right)_{2}\right]}\right.$} & 5.9 & 4.3 \\
\hline
\end{tabular}

the associated uncertainty is inherently large as the prediction uses surface tension values from a limited temperature range and the temperature extrapolation is considerable and since at the critical point the pressure becomes the critical pressure [35,36]. Therefore, they should be interpreted as semi-quantitative even though reasonable estimations, in good agreement with those obtained by molecular simulation calculations, are obtained [37]. In any case, some tendencies can be observed. The highest critical temperature is obtained for the FIL based on the pyridinium cation. Interestingly, in contrast, lower than usual critical temperatures (as compared to those of non-fluorinated ILs) are predicted for FILs with a high num-

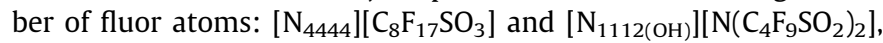
which present 17 and 18 atoms of fluor, respectively. It is well known that fluorinated compounds tend to be much more volatile than their hydrogenated counterparts (for instance, perfluoroalkanes versus alkanes) [38]. Therefore, these semi-quantitative predictions allow us speculating that the same may be true in the case of ionic liquids.

\subsection{Thermophysical properties}

The experimental density, dynamic viscosity, refractive index and ionic conductivities of $\left[\mathrm{C}_{2} \mathrm{C}_{1} \mathrm{py}\right]\left[\mathrm{C}_{4} \mathrm{~F}_{9} \mathrm{CO}_{2}\right]$ and $\left[\mathrm{N}_{1112(\mathrm{OH})}\right]$ $\left[\mathrm{N}\left(\mathrm{C}_{4} \mathrm{~F}_{9} \mathrm{SO}_{2}\right)_{2}\right]$ as a function of temperature are listed in table 6 . The thermophysical properties for the other FILs were previously published [7] and are used in this paper for comparison purposes. The temperature dependence of the density and refractive index was studied applying the following expressions:

$\ln \rho=A_{0}+A_{1} T$

$n_{\mathrm{D}}=B_{0}+B_{1} T$

where $T$ is the absolute temperature and $A_{0}, B_{0}, A_{1}$ and $B_{1}$ are adjustable parameters. The correlation parameters are given in table 7 together with the standard deviations $(\sigma)$. These deviations were calculated by applying the following expression:

$\sigma=\left(\frac{\sum_{i}^{n_{\text {DAT }}\left(z_{\text {exp }}-z_{\text {adjust }}\right)^{2}}}{n_{\text {DAT }}}\right)^{1 / 2}$

where property values and the number of experimental and adjustable data are represented by $z$ and $n_{\text {DAT }}$, respectively.

Arrhenius fittings for fluidity (1/viscosity), $\phi$, and ionic conductivity, $k$, were well carried out using the Vogel-Fulcher-Tammann (VFT) equation:

$\phi=\phi_{0} \exp \left(\frac{-B}{T-T_{0}}\right)$

$\kappa=\kappa_{0} \exp \left(\frac{-B^{\prime}}{T-T_{0}^{\prime}}\right)$

where $\phi_{0}, k_{0}, B, B^{\prime}, T_{0}$ and $T_{0}^{\prime}$ are adjustable parameters. table 7 summarizes the best-fit parameters of these properties.

Density and fluidity results are illustrated in figure 3 . It is observed that $\left[\mathrm{N}_{1112(\mathrm{OH})}\right]\left[\mathrm{N}\left(\mathrm{C}_{4} \mathrm{~F}_{9} \mathrm{SO}_{2}\right)_{2}\right]$ presents the highest density but not the highest viscosity, which belongs to $\left[\mathrm{N}_{4444}\right]\left[\mathrm{C}_{4} \mathrm{~F}_{9} \mathrm{SO}_{3}\right]$. Furthermore, it is clear that the increase in density for FILs based 
TABLE 5

Estimated, hypothetical critical temperatures $\left(T_{c} / \mathrm{K}\right)$ using both the Eötvös (Eot) [21] and the Guggenheim (Gug) [22] equations. The expanded uncertainty with an approximately $95 \%$ level of confidence is $T=100 \mathrm{~K}$.

\begin{tabular}{lll}
\hline & $10^{-3}\left(T_{\mathrm{c}, \text { Eot }}\right) / \mathrm{K}$ & $10^{-3}\left(T_{\mathrm{c}, \text { Gug }}\right) / \mathrm{K}$ \\
\hline$\left[\mathrm{N}_{4444}\right]\left[\mathrm{C}_{8} \mathrm{~F}_{17} \mathrm{SO}_{3}\right]$ & 0.80 & 0.82 \\
{$\left[\mathrm{~N}_{4444}\right]\left[\mathrm{C}_{4} \mathrm{~F}_{9} \mathrm{SO}_{3}\right]$} & 1.11 & 1.03 \\
{$\left[\mathrm{C}_{2} \mathrm{C}_{1} \mathrm{py}\right]\left[\mathrm{C}_{4} \mathrm{~F}_{9} \mathrm{SO}_{3}\right]$} & 1.34 & 1.18 \\
{$\left[\mathrm{C}_{2} \mathrm{C}_{1} \mathrm{py}\right]\left[\mathrm{C}_{4} \mathrm{~F}_{9} \mathrm{CO}_{2}\right]$} & 1.30 & 1.10 \\
{$\left[\mathrm{~N}_{1112(\mathrm{OH})}\right]\left[\mathrm{N}_{\left.\left(\mathrm{C}_{4} \mathrm{~F}_{9} \mathrm{SO}_{2}\right)_{2}\right]}\right.$} & 0.85 & 0.85 \\
\hline
\end{tabular}

on the $\left[\mathrm{N}_{4444}\right]^{+}$cation is related to the increment of the anionic perfluoroalkyl chain length, as expected from the recent work of some of the authors [4], in contrast with the density reduction that occurs when increasing the hydrogenated alkyl chain length of either cation or anion in ionic liquids [39]. Another interesting point is that sulfonate anions show higher densities and viscosities than carboxylate anions for FILs based on the $\left[\mathrm{C}_{2} \mathrm{C}_{1} \mathrm{py}\right]^{+}$cation. This same cation, $\left[\mathrm{C}_{2} \mathrm{C}_{1} \text { py }\right]^{+}$, induces an increase in the fluidity and density when compared with the $\left[\mathrm{N}_{4444}\right]^{+}$cation for FILs based on the perfluorobutanesulfonate anion.

Density data were used to derive the isobaric thermal expansion coefficient, $\alpha_{p}$. This coefficient is directly related to the temperature derivative of the density through the equation:

$\alpha_{\mathrm{p}}=-\left(\frac{\partial \ln \rho}{\partial T}\right)_{\mathrm{p}}$

The isobaric thermal expansion coefficients of these FILs correspond to the symmetric of the $A_{1}$ parameter (equation (5)), obtained from the density fitting, and are shown in table 7 . The overall standard uncertainty of the calculated $\alpha_{\mathrm{p}}$ values is $4 \%$. From the definition of $\alpha_{\mathrm{p}}$, the use of a linear fitting of $\ln (\rho) v s T$ originates a temperature independent thermal expansion coefficient. The results obtained for FILs are lower than those for most organic compounds, e.g. toluene has a $\alpha_{\mathrm{p}}=11 \cdot 10^{-4} \mathrm{~K}^{-1}$, and are higher than those obtained for molten salts, e.g. $\mathrm{KCl}$ has a $\alpha_{\mathrm{p}}=3.6 \cdot 10^{-4} \mathrm{~K}^{-1}$ [40]. Comparing the thermal expansion coefficient of FILs with non-fluorinated ionic liquids, the values obtained fall in the upper range $[41,42]$.

\subsection{Free volume effects}

The refractive index can be used to measure the electronic polarizability of a molecule and can provide useful information when studying the forces between molecules or their behavior in solution [3]. The Lorenz-Lorentz equation relates the electronic polarizability, $\alpha_{\mathrm{e}}$, with the refractive index, $n_{\mathrm{D}}$, and can also be expressed in terms of the molar refraction, or molar polarizability [43], $R_{\mathrm{m}}$, using the expression:

$R_{\mathrm{m}}=\frac{N_{\mathrm{A}} \alpha_{\mathrm{e}}}{3 \varepsilon_{0}}=\left(\frac{n_{\mathrm{D}}^{2}-1}{n_{\mathrm{D}}^{2}+2}\right) V_{\mathrm{m}}$

where $N_{\mathrm{A}}$ is Avogadro's constant, $\varepsilon$ is the dielectric constant, and $V_{\mathrm{m}}$ is the molar volume. The values of the calculated molar refractions for the studied FILs are listed in table 8. The relation between polarizability and the refraction index shown above can provide important information about the behavior of a liquid as a solvent media as it constitutes a measure of the importance of the dispersion forces on the cohesion of the liquid. Therefore, solvents with a large refraction index, and, hence, great polarizability, should enjoy particularly strong dispersion forces [44], whilst also constituting good solvents for species possessing high polarizabilities.

Molar refractions can be considered as a measure of the hardcore molecular volumes because the electronic polarizability can be related to a spherical molecular radius [3], $a$, by:

$\alpha_{\mathrm{e}}=4 \pi \varepsilon_{0} a^{3}$

and equation (11) can be re-expressed in the following form:

$n_{\mathrm{D}}-1=3\left(\frac{V_{\mathrm{m}}}{R_{\mathrm{m}}-1}\right)^{-1}=3\left(\frac{R_{\mathrm{m}}}{f_{\mathrm{m}}}\right)$

where $f_{\mathrm{m}}$ is the free volume defined as:

$f_{\mathrm{m}}=\left(V_{\mathrm{m}}-R_{\mathrm{m}}\right)$

which means that the refractive index is directly proportional to the occupied part of the molar volume, $R_{\mathrm{m}}$, being then considered as the hard-core molecular volume $[45,46]$. The aforementioned methodology is strictly valid when only dispersion forces are present, which is not the case for ionic liquids. However, the dispersion forces component in ILs is significant as opposed to common inorganic molten salts. Therefore, simply based on the dispersion forces component, we have calculated the relative ratio of free volume over molar volume using as reference the $\left[\mathrm{C}_{2} \mathrm{C}_{1}\right.$ py $]\left[\mathrm{C}_{4} \mathrm{~F}_{9} \mathrm{CO}_{2}\right]$ (FIL with the lowest fraction of free volume). The ratios for these FILs decreases in the following order: $\left[\mathrm{N}_{1112(\mathrm{OH})}\right]\left[\mathrm{N}\left(\mathrm{C}_{4} \mathrm{~F}_{9} \mathrm{SO}_{2}\right)_{2}\right]>\left[\mathrm{N}_{4444}\right]\left[\mathrm{C}_{8} \mathrm{~F}_{17} \mathrm{SO}_{3}\right]>\left[\mathrm{N}_{4444}\right]$ $\left[\mathrm{C}_{4} \mathrm{~F}_{9} \mathrm{SO}_{3}\right]>\left[\mathrm{C}_{2} \mathrm{C}_{1} \mathrm{py}\right]\left[\mathrm{C}_{4} \mathrm{~F}_{9} \mathrm{SO}_{3}\right]>\left[\mathrm{C}_{2} \mathrm{C}_{1}\right.$ py $]\left[\mathrm{C}_{4} \mathrm{~F}_{9} \mathrm{CO}_{2}\right]$. These results confirm the previous observation of some of the authors [7], that the proportion of free volume increases with the increment of the anionic fluoroalkyl chain length (for instance, $\left[\mathrm{C}_{4} \mathrm{~F}_{9} \mathrm{SO}_{3} \text { ) }\right]^{-}$versus

TABLE 6

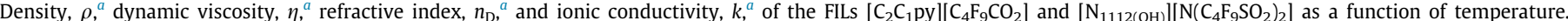
Experiments performed under a typical average laboratory atmospheric pressure of 1.015 bar. $^{b}$

\begin{tabular}{|c|c|c|c|c|c|c|c|c|c|}
\hline$T / \mathrm{K}$ & $\rho / \mathrm{g} \cdot \mathrm{cm}^{-3}$ & $\eta / \mathrm{mPa} \cdot \mathrm{s}$ & $n_{\mathrm{D}}$ & $\mathrm{k} / \mathrm{mS} \cdot \mathrm{cm}^{-1}$ & $T / \mathrm{K}$ & $\rho / \mathrm{g} \cdot \mathrm{cm}^{-3}$ & $\eta / \mathrm{mPa} \cdot \mathrm{s}$ & $n_{\mathrm{D}}$ & $\mathrm{k} / \mathrm{mS} \cdot \mathrm{cm}^{-1}$ \\
\hline \multicolumn{5}{|c|}{$\left[\mathrm{C}_{2} \mathrm{C}_{1} \mathrm{py}\right]\left[\mathrm{C}_{4} \mathrm{~F}_{9} \mathrm{CO}_{2}\right]$} & \multicolumn{5}{|c|}{$\left[\mathrm{N}_{1112(\mathrm{OH})}\right]\left[\mathrm{N}\left(\mathrm{C}_{4} \mathrm{~F}_{9} \mathrm{SO}_{2}\right)_{2}\right]$} \\
\hline 293.15 & 1.4587 & 196.0 & 1.42282 & 0.915 & & & & & \\
\hline 298.15 & 1.4536 & 147.1 & 1.42137 & 1.20 & & & & & \\
\hline 303.15 & 1.4486 & 110.8 & 1.41990 & 1.55 & & & & & \\
\hline 308.15 & 1.4436 & 85.39 & 1.41844 & 1.94 & 308.15 & $1.6794^{c}$ & $1338^{c}$ & $1.37365^{c}$ & $0.096^{c}$ \\
\hline 313.15 & 1.4387 & 67.81 & 1.41697 & 2.39 & 313.15 & 1.6736 & 947.1 & 1.37234 & 0.128 \\
\hline 318.15 & 1.4337 & 53.67 & 1.41553 & 2.89 & 318.15 & 1.6676 & 684.6 & 1.37103 & 0.170 \\
\hline 323.15 & 1.4289 & 43.60 & 1.41406 & 3.55 & 323.15 & 1.6616 & 506.1 & 1.36975 & 0.227 \\
\hline 328.15 & 1.4240 & 35.94 & 1.41260 & & 328.15 & 1.6559 & 379.9 & 1.36845 & \\
\hline 333.15 & 1.4192 & 30.35 & 1.41114 & & 333.15 & 1.6501 & 290.3 & 1.36714 & \\
\hline 338.15 & 1.4143 & 25.32 & 1.40955 & & 338.15 & 1.6444 & 224.8 & 1.36590 & \\
\hline 343.15 & 1.4094 & 21.61 & 1.40811 & & 343.15 & 1.6388 & 176.7 & 1.36463 & \\
\hline 348.15 & 1.4045 & 18.61 & 1.40672 & & 348.15 & 1.6331 & 140.7 & 1.36338 & \\
\hline 353.15 & 1.3995 & 16.39 & 1.40531 & & 353.15 & 1.6272 & 113.4 & 1.36212 & \\
\hline
\end{tabular}

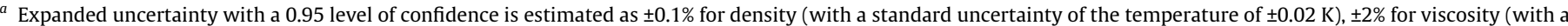

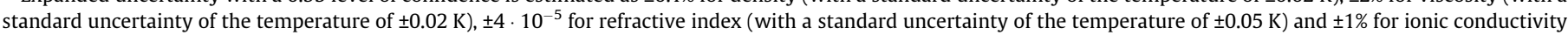
(with a standard uncertainty of the temperature of $\pm 0.1 \mathrm{~K}$ ).

${ }^{b}$ Standard uncertainty of \pm 0.01 bar.

${ }^{c}$ Physical properties of supercooled ionic liquid. 
TABLE 7

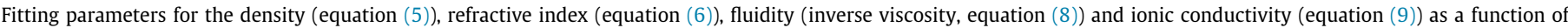

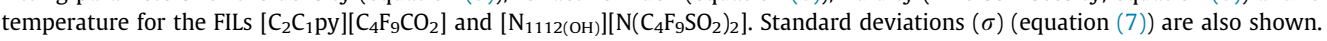

\begin{tabular}{|c|c|c|c|c|}
\hline $\ln \rho / \mathrm{g} \cdot \mathrm{cm}^{-3}$ & $A_{0}=0.57912$ & $\begin{array}{c}{\left[C_{2} C_{1} p y\right]\left[C_{4} F_{9} C O_{2}\right]} \\
A_{1}=-6.8776 \cdot 10^{-4}\end{array}$ & & $\sigma=5.16 \cdot 10^{-5}$ \\
\hline$n_{\mathrm{D}}$ & $B_{0}=1.50875$ & $B_{1}=-2.9309 \cdot 10^{-4}$ & & $\sigma=3.92 \cdot 10^{-5}$ \\
\hline$\phi / \mathrm{mPa}^{-1} \cdot \mathrm{s}^{-1}$ & $\phi_{0}=4.67$ & $B=704.80$ & $T_{0}=190.54$ & $\sigma=1.91 \cdot 10^{-4}$ \\
\hline $\mathrm{k} / \mathrm{mS} \cdot \mathrm{cm}^{-1}$ & $k_{0}=912.29$ & $B^{\prime}=852.77$ & $T_{0}^{\prime}=169.66$ & $\sigma=1.34 \cdot 10^{-2}$ \\
\hline $\ln \rho / \mathrm{g} \cdot \mathrm{cm}^{-3}$ & $A_{0}=0.73393$ & $\begin{array}{c}{\left[\mathrm{N}_{1112(\mathrm{OH})}\right]\left[N\left(\mathrm{C}_{4} \mathrm{~F}_{9} \mathrm{SO}_{2}\right)_{2}\right]} \\
A_{1}=-6.9946 \cdot 10^{-4}\end{array}$ & & $\sigma=5.73 \cdot 10^{-5}$ \\
\hline$n_{\mathrm{D}}$ & $B_{0}=1.45257$ & $B_{1}=-2.5625 \cdot 10^{-4}$ & & $\sigma=3.16 \cdot 10^{-5}$ \\
\hline$\phi / \mathrm{mPa}^{-1} \cdot \mathrm{s}^{-1}$ & $\phi_{0}=1.63$ & $B=707.67$ & $T_{0}=217.84$ & $\sigma=7.77 \cdot 10^{-5}$ \\
\hline $\mathrm{k} / \mathrm{mS} \cdot \mathrm{cm}^{-1}$ & $k_{0}=820.51$ & $B^{\prime}=1275.05$ & $T_{0}^{\prime}=167.65$ & $\sigma=1.33 \cdot 10^{-5}$ \\
\hline
\end{tabular}

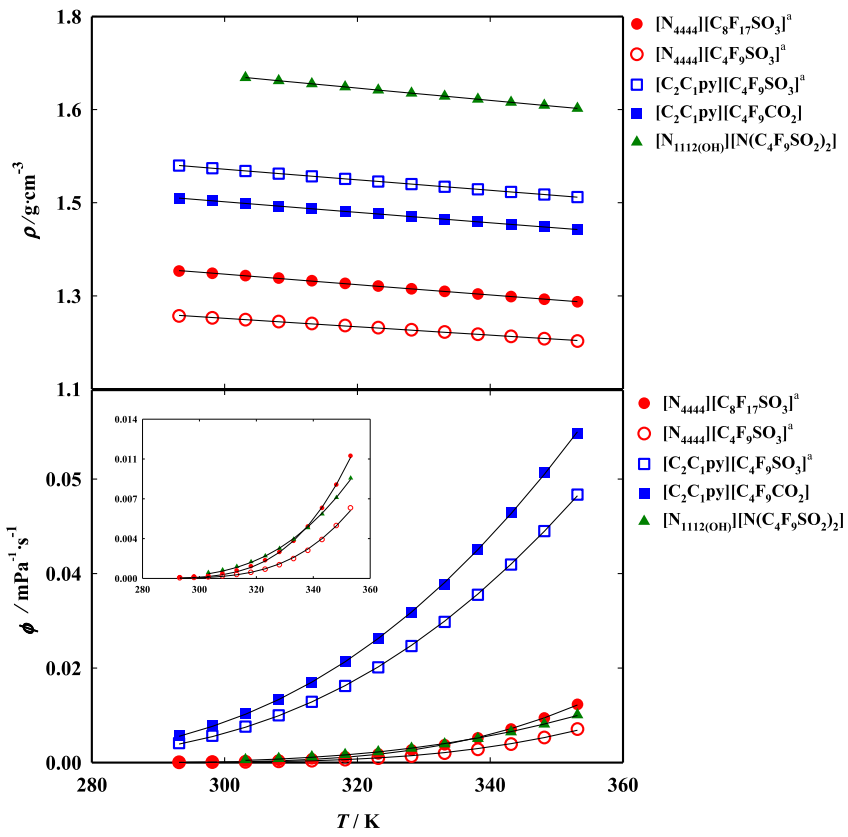

FIGURE 3. Density, fluidity and respective fitted curves as a function of temperature of the studied FILs and comparison with previous experimental data ( ${ }^{a}$ from reference [7]). The inset shows a zoom for the more viscous FILs.

$\left.\left[\mathrm{C}_{8} \mathrm{~F}_{17} \mathrm{SO}_{3}\right)\right]^{-}$for FILs based on the $\left[\mathrm{N}_{4444}\right]^{+}$cation). Also, the percentage of free volume for FILs based on the $\left[\mathrm{C}_{2} \mathrm{C}_{1} \mathrm{py}\right]^{+}$cation is slightly higher for sulfonate-based than for carboxylate-based anions. The analysis of these free volumes effects can be related to the solubility of low molecular weight solutes or gases in these ionic liquids [4749]. Besides, refractive data can be useful for evaluating the importance of the dispersive molecular interactions and the size of the

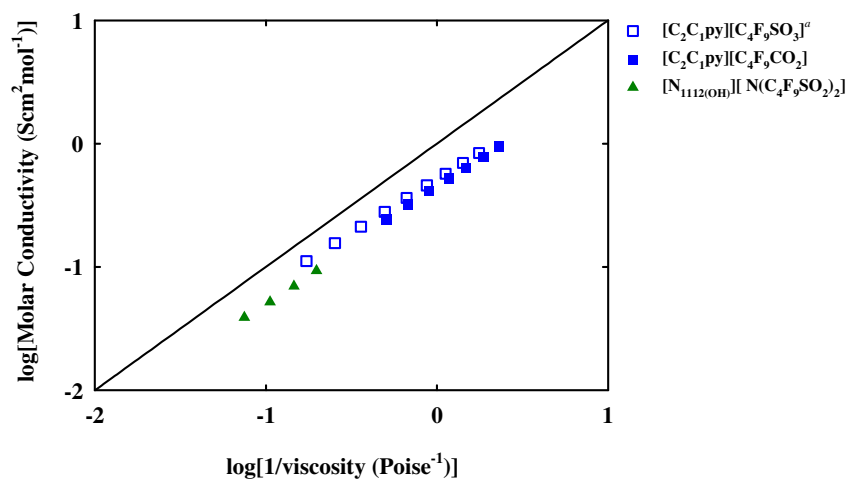

FIGURE 4. Walden plot of the studied FILs and comparison with previous experimental data ( ${ }^{a}$ from reference [7]).

nonpolar domains (dominated by dispersive molecular interactions) in the pure ionic liquids or mixtures with ionic liquids [3].

\subsection{Walden plot}

The ionic conductivities of ionic liquids are mainly governed by the molar concentration of ions present in the fluid and their fluidity. The Walden plot is a useful tool for measuring the ionicity of these compounds, since it establishes a relationship between these two properties, molar conductivity and fluidity [25]. Figure 4 illustrates the Walden plot for the FILs studied in this work where the straight line fixes the position of the "ideal" Walden line corresponding to a diluted aqueous $\mathrm{KCl}$ solution (system known to be fully dissociated and to have ions of equal mobility). The Walden plot demonstrates linear behavior with temperature for each FIL. The differences between carboxylate and sulfonate anions are

TABLE 8

Values of calculated molar volume, $V_{m}$, and molar refraction, $R_{m}$, as a function of temperature for the studied FILs.

\begin{tabular}{|c|c|c|c|c|c|}
\hline$T / K$ & $V_{\mathrm{m}} / \mathrm{cm}^{3} \cdot \mathrm{mol}^{-1}$ & $R_{\mathrm{m}} / \mathrm{cm}^{3} \cdot \mathrm{mol}^{-1}$ & $T / \mathrm{K}$ & $V_{\mathrm{m}} / \mathrm{cm}^{3} \cdot \mathrm{mol}^{-1}$ & $R_{\mathrm{m}} / \mathrm{cm}^{3} \cdot \mathrm{mol}^{-1}$ \\
\hline \multicolumn{3}{|c|}{$\left[C_{2} C_{1} p y\right]\left[C_{4} F_{9} C O_{2}\right]$} & \multicolumn{3}{|c|}{$\left[\mathrm{N}_{1112(\mathrm{OH})}\right]\left[\mathrm{N}\left(\mathrm{C}_{4} \mathrm{~F}_{9} \mathrm{SO}_{2}\right)_{2}\right]$} \\
\hline 293.15 & 264.06 & 67.22 & & & \\
\hline 298.15 & 264.98 & 67.25 & & & \\
\hline 303.15 & 265.91 & 67.28 & & & \\
\hline 308.15 & 266.82 & 67.30 & 308.15 & 407.46 & 92.97 \\
\hline 313.15 & 267.74 & 67.33 & 313.15 & 408.88 & 93.00 \\
\hline 318.15 & 268.66 & 67.35 & 318.15 & 410.33 & 93.04 \\
\hline 323.15 & 269.58 & 67.37 & 323.15 & 411.81 & 93.09 \\
\hline 328.15 & 270.50 & 67.39 & 328.15 & 413.25 & 93.12 \\
\hline 333.15 & 271.42 & 67.41 & 333.15 & 414.68 & 93.15 \\
\hline 338.15 & 272.35 & 67.41 & 338.15 & 416.12 & 93.19 \\
\hline 343.15 & 273.30 & 67.44 & 343.15 & 417.55 & 93.21 \\
\hline 348.15 & 274.26 & 67.47 & 348.15 & 419.00 & 93.25 \\
\hline 353.15 & 275.22 & 67.50 & 353.15 & 420.52 & 93.30 \\
\hline
\end{tabular}


negligible, with a slightly higher value for FILs based on the sulfonate anion.

\section{Conclusions}

In this work, the decomposition temperature, melting point, density, refractive index, surface tension, dynamic viscosity and ionic conductivity data for eight fluorinated ionic liquids were studied. The different thermophysical and surface properties were measured as a function of temperature at atmospheric pressure. The knowledge of the physical properties of these fluorinated ionic liquids is important both at a fundamental (aiming at understanding their behavior) and applied level. The results show that FILs based on the perfluorobutanesulfonate anion exhibit the best thermal properties (melting point and decomposition temperature). Surface tension data for these FILs indicate that they present the lowest values reported up to date for ionic liquids. Thermodynamic functions, such as surface entropies and surface enthalpies, are also lower than those for non-fluorinated ionic liquids implying a high surface organization and structured liquid phase. The semiquantitative predictions of the hypothetical critical temperatures of these FILs suggest that their volatility shall markedly increase with increasing fluoroalkyl chain length.

The thermal expansion coefficient was obtained from the density change with temperature. The FILs studied in this work show a lower volume expansivity or thermal expansion than traditional organic compounds. The analysis of the free volume effects can be related to the solubility of low molecular weight solutes or gases. The increment of the anionic fluoroalkyl chain increases both the importance of the dispersive forces and the percentage of free volume. Finally, Walden plots were used to evaluate the ionicity of the pure fluorinated ionic liquids. The values obtained are similar to those shown by other pure ionic liquids.

\section{Acknowledgments}

The authors wish to thank M. M. Piñeiro from University of Vigo for his contribution to this work and Fundação para a Ciência e a Tecnologia (FCT/MCTES - Ministério da Ciência, Tecnologia e Ensino Superior, Portugal) for financial support through Grants SFRH/ BD/100563/2014 and SFRH/BPD/82264/2011, (N.S.M.V. and P.J.C), contracts under Investigator FCT 2014 (A.B.P. and J.M.M.A.) and 2012 (J.M.S.S.E), and through projects PTDC/EQU-FTT/118800/2010, PTDC/CTM-NAN/121274/2010, IF/00210/2014/CP1244/CT0003, UID/Multi/04551/2013 and UID/CTM/50011/2013. M.G. Freire acknowledges the European Research Council (ERC) for the Starting Grant ERC-2013-StG-337753. The NMR spectrometers are part of The National NMR Facility, supported by FCT/MEC (RECI/BBBBQB/0230/2012).

\section{Appendix A. Supplementary data}

Supplementary data associated with this article can be found, in the online version, at http://dx.doi.org/10.1016/j.jct.2016.02.013.

\section{References}

[1] S. Aparicio, M. Atilhan, F. Karadas, Ind. Chem. Res. 49 (2010) 9580-9595.

[2] N. Papaiconomou, O. Zech, P. Bauduin, J.M. Lévêque, W. Kunz, Electrochim. Acta 70 (2012) 124-130.

[3] M. Tariq, P.A.S. Forte, M.F.C. Gomes, J.N.C. Lopes, L.P.N. Rebelo, J. Chem. Thermodyn. 41 (2009) 790-798.

[4] N.S.M. Vieira, P.M. Reis, K. Shimizu, O.A. Cortes, I.M. Marrucho, J.M.M. Araújo, J. M.S.S. Esperança, J.N.C. Lopes, A.B. Pereiro, L.P.N. Rebelo, RSC Adv. 5 (2015) 65337-65350.

[5] S. Stolte, J. Arning, U. Bottin-Weber, A. Muller, W. Pitner, U. Welz-Biermann, B. Jastorffa, J. Ranke, Green Chem. 9 (2007) 760-767.
[6] S. Stolte, J. Arning, U. Bottin-Weber, M. Matzke, F. Stock, K. Thiele, M. Uerdingen, U. Welz-Biermann, B. Jastorffa, J. Ranke, Green Chem. 8 (2006) 621-629.

[7] A.B. Pereiro, J.M.M. Araújo, S. Martinho, F. Alves, S. Nunes, A. Matias, C.M.M. Duarte, L.P.N. Rebelo, I.M. Marrucho, A.C.S. Sustain, Chem. Eng. 1 (2013) $427-$ 439.

[8] N.V. Plechkova, K.R. Seddon, Chem. Soc. Rev. 37 (2008) 123-150.

[9] R.D. Rogers, K.R. Seddon, Science 32 (2003) 792-793.

[10] C. Florindo, J.M.M. Araújo, F. Alves, C. Matos, R. Ferraz, C. Prudêncio, J.P. Noronha, Z. Petrovski, L. Branco, L.P.N. Rebelo, I.M. Marrucho, Int. J. Pharm. 456 (2013) 553-559.

[11] R. Ferraz, L.C. Branco, I.M. Marrucho, J.M.M. Araújo, L.P.N. Rebelo, M.N. Ponte, C. Prudêncio, J.P. Noronha, Z. Petrovski, Med. Chem. Commun. 3 (2012) 494497.

[12] I.M. Marrucho, L.C. Branco, L.P.N. Rebelo, Annu. Rev. Chem. Biomol. Eng. 5 (2014) 527-546.

[13] J.M.M. Araújo, C. Florindo, A.B. Pereiro, N.S.M. Vieira, A. Matias, C.M.M. Duarte, L.P.N. Rebelo, I.M. Marrucho, RSC Adv. 4 (2014) 28126-28132.

[14] A.B. Pereiro, L.C. Tomé, S. Martinho, L.P.N. Rebelo, I.M. Marrucho, Ind. Eng. Chem. Res. 52 (2013) 4994-5001.

[15] J.G. Riess, Curr. Opin. Colloid Interface Sci. 14 (2009) 294-304.

[16] M.P. Krafft, J.G. Riess, J. Polym. Sci., Part A: Polym. Chem. 45 (2007) 1185-1198.

[17] J.G. Riess, M.P. Krafft, Mater. Res. Soc. Bull. 24 (1999) 42-48.

[18] A.B. Pereiro, M.J. Pastoriza-Gallego, K. Shimizu, I.M. Marrucho, J.N.C. Lopes, M. M. Piñeiro, L.P.N. Rebelo, J. Phys. Chem. B 117 (2013) 10826-10833.

[19] R. Berger, G. Resnati, P. Metrangolo, E. Weber, J. Hulliger, Chem. Soc. Rev. 40 (2011) 3496-3508.

[20] A.B. Pereiro, J.M.M. Araujo, F.S. Teixeira, I.M. Marrucho, M.M. Piñeiro, L.P.N. Rebelo, Langmuir 31 (2015) 1283-1295.

[21] L. Shereshefsky, J. Phys. Chem. 35 (1931) 1712-1720.

[22] E.A. Guggenheim, J. Chem. Phys. 13 (1945) 253.

[23] K. Fukumoto, M. Yoshizawa, H. Ohno, J. Am. Chem. Soc. 127 (2005) 2398-2399.

[24] H.F.D. Almeida, M.G. Freire, A.M. Fernandes, J.A. Lopes da Silva, P. Morgado, K. Shimizu, E.J.M. Filipe, J.N.C. Lopes, L.M.N.B.F. Santos, J.A.P. Coutinho, Langmuir 30 (2014) 6408-6418.

[25] A.B. Pereiro, J.M.M. Araújo, F.S. Oliveira, C.E.S. Bernardes, J.M.S.S. Esperança, J. N.C. Lopes, I.M. Marrucho, L.P.N. Rebelo, Chem. Commun. 48 (2012) 36563658.

[26] A.W. Adamson, A.P. Gast, Physical Chemistry of Surfaces, sixth ed., John Wiley, 1997.

[27] D. Instruments, Surface tension values of some common test liquids for surface energy analysis, 2006, available online: <http://www.surface-tension.de/> [accessed: 16-Dec-2014].

[28] M. Tariq, M.G. Freire, B. Saramago, J.A.P. Coutinho, J.N.C. Lopes, L.P.N. Rebelo, Chem. Soc. Rev. 41 (2012) 829-868.

[29] W. Jiang, Y. Wang, T. Yan, G.A. Voth, J. Phys. Chem. C 112 (2008) 1132-1139.

[30] M.G. Freire, P.J. Carvalho, A.M. Fernandes, I.M. Marrucho, A.J. Queimada, J.A.P. Coutinho, J. Colloid Interface Sci. 314 (2007) 621-630.

[31] H.F.D. Almeida, J.A. Lopes-da-Silva, M.G. Freire, J.A.P. Coutinho, J. Chem. Thermodyn. 57 (2013) 372-379.

[32] H.F.D. Almeida, A.R.R. Teles, J. Lopes-da-Silva, M.G. Freire, J.A.P. Coutinho, J. Chem. Thermodyn. 54 (2012) 49-54.

[33] L.P.N. Rebelo, J.N.C. Lopes, J.M.S.S. Esperança, E. Filipe, J. Phys. Chem. B 109 (2005) 6040-6043.

[34] L.P.N. Rebelo, J.N. Canongia Lopes, J.M.S.S. Esperança, J. Magee, M. Tariq, L.M.N. B.F. Santos, J. Chem. Eng. Data 55 (2010) 3-12.

[35] B.E. Poling, J.M. Prausnitz, J.P. O'Connell, The Properties of Gases and Liquids, fifth ed., McGraw-Hill, New York, 2001.

[36] K.S. Birdi, Handbook of Surface and Colloid Chemistry, first ed., CRC Press, 1997.

[37] N. Rai, E.J. Maginn, J. Phys. Chem. Lett. 2 (2011) 1439-1443.

[38] D.M. Lemal, J. Org. Chem. 69 (2004) 1-11.

[39] M. Blesic, M. Swadźba-Kwaśny, T. Belhocine, H.Q.N. Gunaratne, J.N.C. Lopes, M. F. Costa Gomes, A.A.H. Pádua, K.R. Seddon, L.P.N. Rebelo, Phys. Chem. Chem. Phys. 11 (2009) 8939-8948.

[40] A.B. Pereiro, P. Verdía, E. Tojo, A. Rodríguez, J. Chem. Data 52 (2007) 377-380.

[41] A.J.L. Costa, M.R.C. Soromenho, K. Shimizu, I.M. Marrucho, J.M.S.S. Esperança, J. N.C. Lopes, L.P.N. Rebelo, ChemPhysChem 13 (2012) 1902-1909.

[42] A.J.L. Costa, J.M.S.S. Esperança, I.M. Marrucho, L.P.N. Rebelo, J. Chem. Eng. Data 56 (2011) 3433-3441.

[43] M.R. Moldover, in: IUPAC Experimental Thermodynamics, Measurement of the Thermodynamic Properties of Single Phases, vol. VI, Elsevier, 2008, pp. 435451.

[44] C. Reichardt, Solvents and Solvent Effects in Organic Chemistry, third ed., Wiley, 2003.

[45] M.A. Iglesias-Otero, J. Troncoso, E. Carballo, L. Romani, J. Chem. Thermodyn. 40 (2008) 949-956.

[46] M. Deetlefs, K. Seddon, M. Shara, Phys. Chem. Chem. Phys. 8 (2006) 642-649.

[47] W.J. Horne, M.S. Shannon, J.E. Bara, J. Chem. Thermodyn. 77 (2014) 190-196.

[48] H.J. Liu, S. Dai, D.E. Jiang, Ind. Eng. Chem. Res. 53 (2014) 10485-10490.

[49] X. Zhao, Q.W. Yang, D. Xu, Z.B. Bao, Y. Zhang, B.G. Su, Q.L. Ren, H.B. Xing, AICHE J. 61 (2015) 2016-2027.

\section{JCT $15-617$}

